\title{
Effect of rosiglitazone on plasma adiponectin levels and arterial stiffness in subjects with prediabetes or non-diabetic metabolic syndrome
}

Sin Gon Kim, Ohk Hyun Ryu, Hee Young Kim, Kye Won Lee, Ji A Seo, Nan Hee Kim, Kyung Mook Choi, Juneyoung Lee ${ }^{1}$, Sei Hyun Baik and Dong Seop Choi

Division of Endocrinology and Metabolism, Department of Internal Medicine and ${ }^{1}$ Department of Preventive Medicine, Anam Hospital, Korea University Medical Center, 126-1, Anamdong 5-ga, Sungbuk-ku, Seoul 136-705, Korea

(Correspondence should be addressed to D S Choi; Email: cdongs@kumc.or.kr)

\begin{abstract}
Objective: Thiazolidinediones have favorable influences on surrogate markers of atherosclerosis such as adiponectin, and arterial stiffness in diabetic patients. However, it is not well known whether these beneficial effects occur in subjects without diabetes, such as prediabetes or the non-diabetic metabolic syndrome (MetS). The present study was therefore designed to evaluate the effectiveness of the insulin-sensitizing agent rosiglitazone on circulating adipocytokine levels and brachial-ankle pulse wave velocity (baPWV) in non-diabetics.

Design and methods: Ninety-nine subjects with prediabetes or non-diabetic MetS were randomly assigned to either rosiglitazone or an untreated control group (50 and 49 subjects respectively). The rosiglitazone group was treated daily for 12 weeks with $4 \mathrm{mg}$ rosiglitazone. All subjects received a $75 \mathrm{~g}$ oral glucose test (OGTT) before and after treatment. In addition, baPWV, together with the levels of adiponectin, resistin, and high sensitivity C-reactive protein (hsCRP) were determined. Results: Rosiglitazone treatment significantly increased circulating adiponectin levels $(P<0.001)$ relative to the control group $(P=0.21)$. Plasma resistin levels were unchanged in both the rosiglitazone-treated and -untreated groups, but baPWV and hsCRP were significantly decreased $(P<0.001$ and $P=0.003$ respectively) in the rosiglitazone group only. Multiple linear regression analysis showed that changes in plasma adiponectin and baPWV were significantly affected by rosiglitazone treatment.

Conclusions: These data suggest that rosiglitazone may have an anti-atherogenic effect in subjects with prediabetes or non-diabetic MetS.
\end{abstract}

European Journal of Endocrinology 154 433-440

\section{Introduction}

Thiazolidinedione (TZD), a peroxisome proliferatoractivated receptor (PPAR)- $\gamma$ agonist is an insulinsensitizing agent and is used to treat patients with type 2 diabetes (T2DM). PPAR- $\gamma$ is found most abundantly in adipocytes (1) but it is also expressed in endothelial cells, vascular smooth muscle cells (VSMCs), macrophages, and T cells (2). PPAR- $\gamma$ agonists reduce the cytokine-induced expression of adhesion molecules in endothelial cells (3), and also inhibit VSMC migration, growth, and proliferation (4). These studies suggested that PPAR- $\gamma$ agonists may inhibit atherosclerotic disease progression. Several human studies have shown that TZDs have beneficial effects on the surrogate endpoints of atherosclerosis, such as high sensitivity C-reactive protein (hsCRP) (5) and carotid intima-media thickness (IMT) (6) in T2DM. Recently, the results of the PROactive (PROspective pioglitAzone Clinical Trial In macroVascular Events) study (7) showed that pioglitazone reduces the composite of all causes of mortality, non-fatal myocardial infarction, and stroke in patients with T2DM who have a high risk of macrovascular events. Moreover, recent data suggest that the beneficial effects of TZDs can be extrapolated to non-diabetic subjects $(8,9)$.

Pulse wave velocity (PWV) is a non-invasive means of measuring arterial stiffness for assessment of atherosclerosis, and many articles have been published on the relationship between PWV and the development of atherosclerotic disease $(10,11)$. Moreover, PWV is believed to be a risk marker (12) and prognostic predictor of atherosclerosis (13). Recently, one study (5) reported that pioglitazone treatment significantly 
reduced brachial-ankle PWV (baPWV), independently of changes in parameters related to glucose metabolism, in T2DM. However, to the best of our knowledge, no article has been published concerning the effect of TZDs on PWV in non-diabetics.

Adipose tissue is now known to express and secrete a variety of bioactive peptides, which are collectively known as adipocytokines (14). These factors include adiponectin, leptin, tumor necrosis factor- $\alpha$, plasminogen activator inhibitor-1, and resistin (14). Adiponectin is an adipocytokine that is highly specific for adipose tissue. Adiponectin may have anti-inflammatory and anti-atherogenic properties (15) and is considered to be an independent risk factor for cardiovascular disease (16). It was recently reported that rosiglitazone increases plasma adiponectin levels in subjects with T2DM (17); however, it is not known whether the level of this protective adipocytokine is increased by TZDs in subjects with prediabetes or the non-diabetic metabolic syndrome (MetS).

Prediabetes (18) and MetS (19) are high-risk states for diabetes and cardiovascular disease respectively. We hypothesized that TZDs may have vasoprotective effects in prediabetes or non-diabetic MetS. This study was therefore undertaken to evaluate the effectiveness of the insulin-sensitizing agent rosiglitazone on circulating adipocytokine levels, which are known to be related to atherosclerosis like adiponectin, and baPWV as a marker of arterial stiffness in subjects with prediabetes or non-diabetic MetS.

\section{Materials, subjects and methods}

\section{Study subjects and study protocol}

A total of 99 subjects (52 men and 47 women, mean age $53.5 \pm 11.4$ years) with prediabetes (31 subjects) or non-diabetic MetS (68 subjects) participated in this study. Prediabetes was defined as a fasting plasma glucose (FBS) level of $100-125 \mathrm{mg} / \mathrm{dl}$ or a $2-\mathrm{h}$ plasma glucose level of $140-199 \mathrm{mg} / \mathrm{dl}$ by a $75 \mathrm{~g}$ oral glucose tolerance test (OGTT) according to the criteria of the American Diabetes Association (18). MetS was defined using the criteria of the National Cholesterol Education Program Adult Treatment Panel III (20), modified in accordance with the World Health Organization's proposed waist circumference cut-off points for Asians (21). Subjects with MetS were required to conform with three or more of the following criteria: (a) a waist circumference of $>90 \mathrm{~cm}$ in men and $>80 \mathrm{~cm}$ in women, (b) serum triglycerides of $\geq 150 \mathrm{mg} / \mathrm{dl}$, (c) high-density lipoprotein (HDL) cholesterol levels $<40 \mathrm{mg} / \mathrm{dl}$ in men and $<50 \mathrm{mg} / \mathrm{dl}$ in women, (d) impaired fasting glucose of 110$125 \mathrm{mg} / \mathrm{dl}$, and (e) a blood pressure of $\geq 130 / 85 \mathrm{mmHg}$ or treated hypertension.

Subjects who had taken a stable dose of anti-hypertensive or lipid-lowering drugs for at least 4 weeks before the study were enrolled, and these medication dosages were maintained throughout the study. The major exclusion criteria were: diabetes mellitus as defined by the American Diabetes Association, a history of treatment or a diagnosis of diabetes mellitus, overt liver disease (aspatate aminotransferase or alanine aminotransferase $>2.5$ times the reference level), alcohol or drug abuse, hormone replacement therapy, edema or renal insufficiency with a serum creatinine level $\geq 2.0$, and heart failure. Informed consent was obtained from all subjects before participation, and the study was approved by the institutional review board of our institution.

Ninety-nine subjects were randomly assigned to each group, 50 to the rosiglitazone treatment group and 49 to the non-treated control group. Rosiglitazone group members received $4 \mathrm{mg}$ rosiglitazone (Glaxo-SmithKline, UK) daily for 12 weeks, and liver function tests were monitored at baseline and at 4-week intervals during the study period. At baseline and after 12 weeks, all subjects were given a $75 \mathrm{~g}$ OGTT. BaPWV, together with adiponectin, resistin and hsCRP levels, and anthropometric data were also obtained. Oral and written information was given by a specialized nurse and dietitian to all subjects about the health benefits of a healthy, low cholesterol diet, and physical activity of moderate intensity for at least $150 \mathrm{~min}$ per week.

\section{Biochemical analyses and baPWV}

Blood samples were drawn after an overnight fast and immediately centrifuged. Serum total cholesterol, triglycerides, HDL cholesterol, and liver enzyme levels were determined enzymatically using a chemical analyzer (Hitachi 747, Tokyo, Japan). Plasma glucose was measured using the glucose oxidase method, and serum insulin levels were measured by immunoradiometric assay (Biosource, Nivelles, Belgium). The homeostasis model of assessment (HOMA), a parameter of insulin resistance, was calculated using baseline glucose and insulin levels as: fasting glucose $(\mathrm{mmol} / \mathrm{l}) \times$ fasting insulin $(\mu \mathrm{U} / \mathrm{ml}) / 22.5$.

hsCRP levels were measured using a CRP ELISA kit (Immunodiagno, Bensheim, Germany), and its intraand interassay coefficients of variation were $6.5 \%$ and $10.4 \%$ respectively. Serum adiponectin and resistin concentrations were determined using enzyme-linked immunosorbent assay using kits developed by the KOMED Institute for Life Science (Seoul, South Korea) (22). The inter- and intra-assay coefficients of variation for adiponectin were $4.63 \%$ and $2.72 \%$ and for resistin they were $5.60 \%$ and $3.73 \%$ respectively.

After a subject had rested in a supine position for 5 min, baPWV was measured using a volume-plethymographic apparatus (model BP-203RPE II; Colin, Komaki, Japan). This instrument simultaneously records baPWV, and the brachial and ankle blood pressures on the left and right sides. Details of this method, its validity, and 
its reproducibility have been described previously by Yamashina et al. (23) and Kubo et al. (24). The interobserver and intra-observer coefficients of variation were $8.4 \%$ and $10.0 \%$ respectively. In this study, baPWV was calculated as the mean of the left and right baPWV values.

\section{Statistical analysis}

All statistical analyses were performed using SAS version 9.1 (SAS institute Inc., Cary, NC, USA). Data are expressed as means \pm S.D. Variables that did not show normal distribution were log-transformed for subsequent analysis. The rosiglitazone-treated and -untreated groups were compared at baseline using the Student's t-test, the chi-squared test, or Fisher's exact test as appropriate. Analysis of changes between baseline and week 12 was performed using the Student's t-test between two groups, and by using the paired $t$-test within groups. Multiple regression analysis using the changes of baPWV or adiponectin as a dependent variable was conducted to determine the relative contributions made by each of the following independent variables: age, gender, body mass index (BMI), weight, waist, fasting glucose, post-OGTT glucose, hemoglobin A1c (HbAlc), HOMA, cholesterol, HDL cholesterol, triglyceride, hsCRP, and systolic and diastolic blood pressure. The stepwise variable selection method was used to choose significant predictor variables. Statistical significance was accepted for $P$ values of $<0.05$.

\section{Results}

\section{Baseline characteristics and safety profile}

The study was fully completed by 85 subjects ( 45 in the rosiglitazone group and 40 in the control group). The most frequent reason for early termination was patient decision to refuse further study (five in the control group). Three subjects were unwilling to attend follow-up, four subjects were excluded by the exclusion criteria from the study soon after randomization, and two subjects in the rosiglitazone group withdrew because of untoward side-effects. Of these two, one experienced dizziness and palpitation, and the other one a mild liver transaminase elevation (from 30 to $75 \mathrm{IU} / \mathrm{l}$ in alanine aminotransferase). No other sideeffects, e.g. serious edema or dyspnea were observed. Baseline characteristics were similar in both groups, except for a significantly higher mean systolic blood pressure in the rosiglitazone group (Table 1).

\section{Changes in various parameters in the two groups}

Anthropometric and metabolic parameters The effects of rosiglitazone on anthropometric and meta- bolic parameters compared with the control group are summarized in Table 2. Only FBS and HOMA were significantly different between baseline and week 12 in the two groups. Whereas FBS and HOMA increased in the control group, FBS decreased and HOMA was unchanged in the rosiglitazone group. Over the 12-week period, rosiglitazone treatment significantly reduced fasting and post-OGTT plasma glucose $(P=0.002$ and $P=0.032$ respectively $)$, and post-OGTT insulin levels $(P=0.044)$. Systolic and diastolic blood pressures $(P=0.001$ and $P<0.001$ respectively) were significantly reduced, but lipid profiles were unchanged in the rosiglitazone group. In the control group, serum triglyceride levels were significantly reduced, blood pressures were unchanged, and FBS levels were increased.

Various atherosclerotic markers including adiponectin and baPWV As shown in Fig. 1, rosiglitazone treatment significantly increased circulating adiponectin levels (from $2.71 \pm 2.17$ to $7.07 \pm 1.77 \mu \mathrm{g} / \mathrm{ml}$, $P<0.001$ ), and significantly reduced baPWV (from $1478.2 \pm 254.6$ to $1390.2 \pm 253.3 \mathrm{~cm} / \mathrm{s}, \quad P<0.001)$ and hsCRP (from $0.16 \pm 2.32$ to $0.09 \pm 2.67 \mathrm{mg} / \mathrm{dl}$, $P<0.01$ ), but no changes were observed in the control group. Plasma resistin levels were unchanged in both groups. The effect of rosiglitazone on atherosclerotic markers was not influenced by the presence of MetS. In the roglitazone group, those without and with MetS (15 and 30 subjects respectively) according to the modified National Cholesterol Education Program Adult Treatment Panel III, showed similar changes in adiponectin levels (3.70 vs $5.19 \mu \mathrm{g} / \mathrm{ml}, P=0.2683)$, PWV $(-80.40$ vs $-91.85 \mathrm{~cm} / \mathrm{s}, P=0.7691)$ and hsCRP $(-0.07$ vs $-0.10 \mathrm{mg} / \mathrm{dl}, P=0.5494)$.

Factors determining the changes in adiponectin and PWV (Table 3) Changes in adiponectin level were significantly associated with treatment status (use of rosiglitazone or control) and triglyceride level by multiple regression analysis. Age and changes in HOMA were borderline significant $(P=0.052$ and $P=0.065$ respectively). Treatment status was attributed to $34.8 \%$ of variance $\left(r^{2}=0.348\right)$, whereas the $r^{2}$ of the final model, where all significant variables were entered, was 0.429. On the other hand, treatment status, age, and changes in diastolic blood pressure and triglyceride were identified as being independently related to baPWV by multiple regression analysis $\left(r^{2}=0.312\right)$.

\section{Discussion}

PWV is a non-invasive straightforward measure for evaluating arterial wall stiffness, and several studies have indicated that this is a good marker of vascular damage. More recently, PWV was considered a risk 
Table 1 Baseline characteristics of subjects in the rosiglitazone $(n=45)$ and control $(n=40)$ groups. *Geometric mean and S.D. values. are given. Logarithmic transformed values were used.

\begin{tabular}{|c|c|c|c|}
\hline & Control & Rosiglitazone & $P$ value $†$ \\
\hline \multicolumn{4}{|l|}{$\operatorname{Sex}(\%)$} \\
\hline Male & $23(57.5)$ & $26(57.8)$ & \multirow[t]{2}{*}{0.9794} \\
\hline Female & $17(42.5)$ & $19(42.2)$ & \\
\hline \multicolumn{4}{|l|}{ Distribution of subgroup (\%) } \\
\hline Prediabetes without MetS & $13(32.5)$ & 15 (33.3) & \multirow[t]{2}{*}{0.9654} \\
\hline With MetS & $27(67.5)$ & $30(66.7)$ & \\
\hline Age (years) & $53.4 \pm 9.8$ & $54.2 \pm 11.9$ & 0.7448 \\
\hline $\mathrm{BMI}$ at baseline $\left(\mathrm{kg} / \mathrm{m}^{2}\right)$ & $26.2 \pm 2.8$ & $27.1 \pm 3.2$ & 0.1384 \\
\hline Weight $(\mathrm{kg})$ & $68.4 \pm 9.9$ & $70.9 \pm 11.6$ & 0.2878 \\
\hline Systolic blood pressure $(\mathrm{mmHg})$ & $127.8 \pm 11.4$ & $133.6 \pm 13.0$ & 0.0336 \\
\hline Diastolic blood pressure (mmHg) & $82.2 \pm 10.9$ & $86.0 \pm 9.5$ & 0.0958 \\
\hline Fasting glucose $(\mathrm{mmol} / \mathrm{l})$ & $6.1 \pm 0.6$ & $6.2 \pm 0.6$ & 0.4794 \\
\hline Post OGTT glucose $(\mathrm{mmol} / \mathrm{l})$ & $8.5 \pm 2.0$ & $8.2 \pm 2.0$ & 0.4741 \\
\hline $\mathrm{HbA} 1 \mathrm{c}(\%)$ & $5.8 \pm 0.4$ & $5.8 \pm 0.4$ & 0.6544 \\
\hline Fasting insulin $(\mathrm{pmol} / \mathrm{l})^{*}$ & $71.0 \pm 10.0$ & $68.2 \pm 10.0$ & 0.5555 \\
\hline Post OGTT insulin (pmol/l/)* & $307.0 \pm 13.6$ & $299.9 \pm 15.1$ & 0.9009 \\
\hline HOMA index* & $2.7 \pm 1.4$ & $2.6 \pm 1.4$ & 0.7126 \\
\hline Total cholesterol (mmol/l) & $5.3 \pm 1.0$ & $5.3 \pm 0.9$ & 0.9493 \\
\hline Triglyceride $(\mathrm{mmol} /)^{*}$ & $2.0 \pm 0.0$ & $1.9 \pm 0.0$ & 0.7520 \\
\hline HDL cholesterol (mmol/l) & $1.2 \pm 0.3$ & $1.2 \pm 0.3$ & 0.6295 \\
\hline LDL cholesterol (mmol/l) & $2.9 \pm 1.0$ & $3.0 \pm 0.7$ & 0.5795 \\
\hline $\mathrm{hsCRP}(\mathrm{mg} / \mathrm{dl})^{*}$ & $0.12 \pm 2.02$ & $0.16 \pm 2.32$ & 0.1416 \\
\hline Serum adiponectin $(\mu \mathrm{g} / \mathrm{ml})^{*}$ & $1.99 \pm 2.21$ & $2.71 \pm 2.17$ & 0.0750 \\
\hline Resistin $(\mathrm{ng} / \mathrm{ml})^{*}$ & $1.36 \pm 5.01$ & $2.50 \pm 3.32$ & 0.0517 \\
\hline baPWV $(\mathrm{cm} / \mathrm{s})$ & $1437.0 \pm 227.1$ & $1478.2 \pm 254.6$ & 0.4350 \\
\hline \multicolumn{4}{|l|}{ Anti-hypertensive agent (\%) } \\
\hline$\beta$-blocker & $1(2.5)$ & $5(11.1)$ & 0.2068 \\
\hline Diuretics & $6(15.0)$ & $5(11.3)$ & 0.6217 \\
\hline Calcium channel blocker & $5(12.5)$ & $11(24.4)$ & 0.1597 \\
\hline Angiotensin receptor blocker & $9(22.5)$ & $8(17.7)$ & 0.5869 \\
\hline \multicolumn{4}{|l|}{ Lipid lowering agent (\%) } \\
\hline Fibrate & $1(2.5)$ & $0(0.0)$ & 0.4643 \\
\hline Statin & $7(17.5)$ & $6(13.6)$ & 0.6249 \\
\hline
\end{tabular}

$\dagger P$ values are by Student's $t$-test or Fisher's exact test (for $\beta$-blocker and Fibrate).

Table 2 Changes of anthropometric and metabolic parameters from baseline to week 12 in the rosiglitazone and control groups. *Geometric mean and S.D. values are given.

\begin{tabular}{|c|c|c|c|c|c|}
\hline & \multicolumn{2}{|c|}{ Control } & \multicolumn{2}{|c|}{ Rosiglitazone } & \multirow[b]{2}{*}{$\boldsymbol{P}$ value $\S$} \\
\hline & Baseline & Follow-up† & Baseline & Follow-up† & \\
\hline BMI $\left(\mathrm{kg} / \mathrm{m}^{2}\right)$ & $26.1 \pm 2.8$ & $25.9 \pm 2.7$ & $27.1 \pm 3.2$ & $26.9 \pm 3.2$ & 0.5454 \\
\hline Weight (kg) & $68.4 \pm 9.9$ & $67.9 \pm 9.7$ & $70.9 \pm 11.6$ & $70.2 \pm 11.4$ & 0.3851 \\
\hline Systolic blood pressure $(\mathrm{mmHq})$ & $127.8 \pm 11.4$ & $125.9 \pm 12.8$ & $133.6 \pm 13.0$ & $127.8 \pm 13.3^{b}$ & 0.1422 \\
\hline Diastolic blood pressure $(\mathrm{mmHg})$ & $82.2 \pm 10.9$ & $81.6 \pm 11.3$ & $86.0 \pm 9.5$ & $80.7 \pm 9.6^{c}$ & 0.0549 \\
\hline Fasting glucose $(\mathrm{mmol} / \mathrm{l})$ & $6.1 \pm 0.6$ & $6.4 \pm 0.7^{\mathrm{a}}$ & $6.2 \pm 0.6$ & $6.0 \pm 0.5^{b}$ & $<.0001$ \\
\hline Post-OGTT glucose (mmol/l) & $8.5 \pm 2.0$ & $8.4 \pm 2.5$ & $8.2 \pm 2.0$ & $7.6 \pm 1.8^{\mathrm{a}}$ & 0.2377 \\
\hline $\mathrm{HbA} 1 \mathrm{c}(\%)$ & $5.8 \pm 0.4$ & $5.7 \pm 0.3$ & $5.8 \pm 0.5$ & $5.7 \pm 0.3$ & 0.6589 \\
\hline Fasting insulin $(\mathrm{pmol} / \mathrm{ml})^{*}$ & $71.0 \pm 10.0$ & $85.4 \pm 10.0^{\mathrm{C}}$ & $68.2 \pm 10.0$ & $71.6 \pm 9.3$ & 0.0738 \\
\hline Post-OGTT insulin (pmol/ml)* & $307.0 \pm 13.6$ & $304.2 \pm 13.6$ & $299.9 \pm 15.1$ & $233.2 \pm 12.2^{\mathrm{a}}$ & 0.1210 \\
\hline HOMA index* & $2.7 \pm 1.4$ & $3.3 \pm 1.4^{\mathrm{c}}$ & $2.6 \pm 1.4$ & $2.67 \pm 1.4$ & 0.0095 \\
\hline Total cholesterol (mmol//) & $5.3 \pm 1.0$ & $5.1 \pm 1.1$ & $5.3 \pm 0.9$ & $5.2 \pm 0.9$ & 0.6132 \\
\hline Triglyceride $(\mathrm{mmol} / \mathrm{l})^{*}$ & $2.0 \pm 0.0$ & $1.6 \pm 0.0^{a}$ & $1.9 \pm 0.0$ & $1.6 \pm 0.0$ & 0.5910 \\
\hline HDL cholesterol (mmol/l) & $1.1 \pm 0.3$ & $1.2 \pm 0.3$ & $1.2 \pm 0.3$ & $1.3 \pm 0.4$ & 0.6655 \\
\hline LDL cholesterol (mmol/l) & $2.9 \pm 1.0$ & $2.9 \pm 1.0$ & $3.0 \pm 0.7$ & $3.0 \pm 0.7$ & 0.7821 \\
\hline
\end{tabular}

† Significant changes from baseline to week 12 are indicated by ${ }^{\mathrm{a}} P<0.05,{ }^{\mathrm{b}} P<0.01$ and ${ }^{\mathrm{c}} P<0.001$ (paired $t$-test).

$\S P$ values were obtained using Student's $t$-test based on changes between baseline and week 12 in each group. 

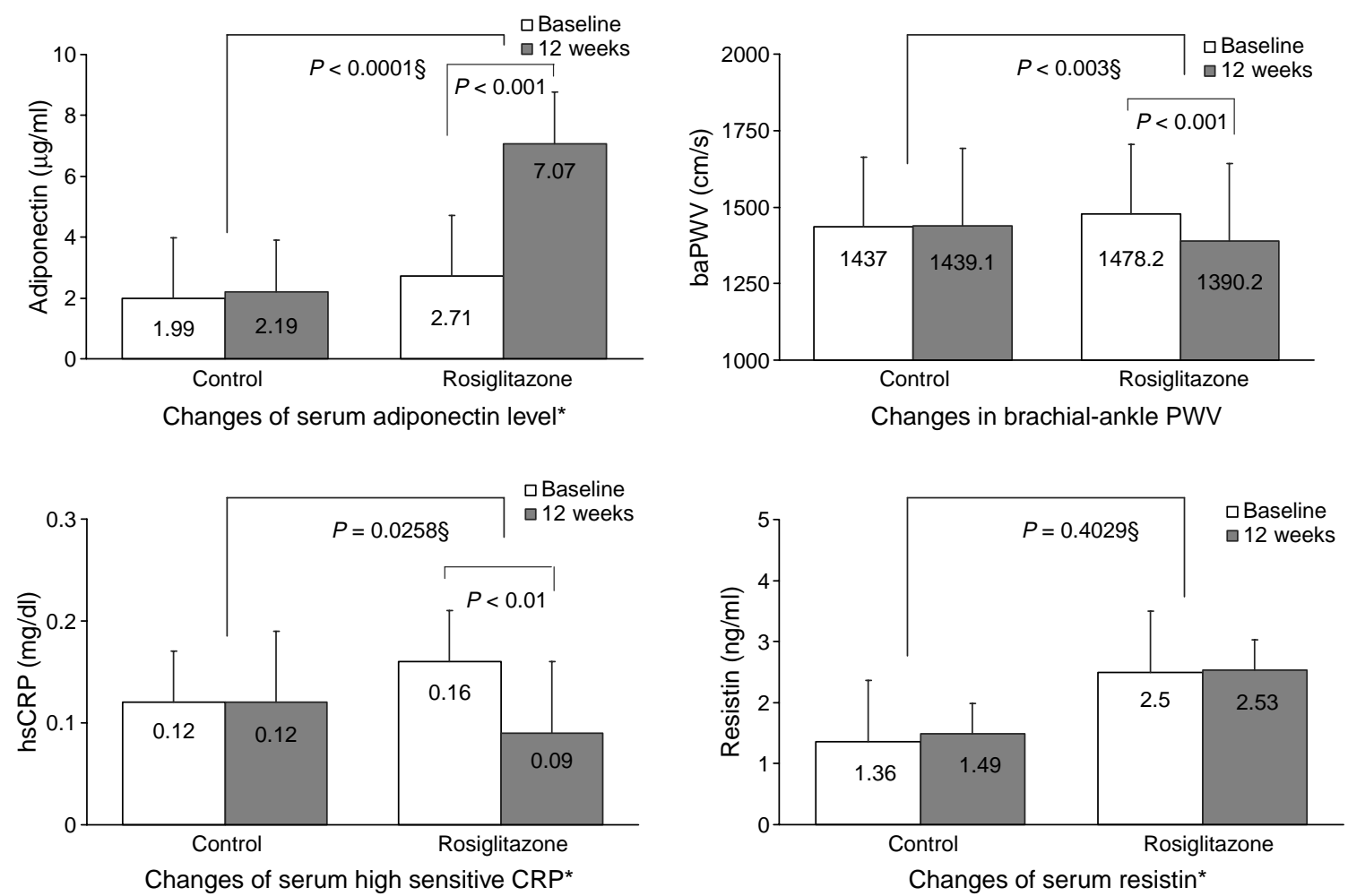

Figure 1 Changes of various atherosclerotic parameters between baseline and week 12 in the rosiglitazone and control groups. *Geometric mean and S.E.M. are given. $§ P$ values were obtained using Student's $t$-test based on changes between baseline and week 12 in each group.

marker (12) and a prognostic predictor of atherosclerosis (13). On the other hand, baPWV is a newly developed device that uses a volume-rendering method. This instrument determines baPWV with simultaneous oscillometric measurement of pulse waves in all four extremities in a short period of time (24). Values of baPWV correlated well with values of aortic PWV (23) and, furthermore, flow-mediated dilation of brachial artery, carotid IMT, and baPWV and heart-carotid PWV were also significantly related to each other (25). Recently, Koji et al. (26) reported that baPWV had a negative predictive value for the presence of coronary artery disease, and suggested that baPWV is a marker of early stage atherosclerosis. Importantly, their results indicate that increased arterial stiffness occurs before the clinical manifestations of atherosclerotic cardiovascular diseases.

The present study demonstrates, for the first time, that the TZD rosiglitazone significantly reduces PWV in non-diabetics. The results of a recent study (27) that investigated the effects of non-TZDs on PWV in African-American subjects with insulin resistance and a normal glucose tolerance test were reported. Interestingly, the effect of non-TZDs on PWV in non-diabetics was the exact reverse of ours. In this study (27), a significant increase in PWV was observed in both glipizide- and metformin-treated groups during the followup period. Compared with these observations, the

Table 3 Multiple regression analysis using the changes of adiponectin or baPWV as dependent variables.

\begin{tabular}{|c|c|c|c|c|c|c|}
\hline \multirow[b]{2}{*}{ Independent variables } & \multicolumn{3}{|c|}{ Change in adiponectin } & \multicolumn{3}{|c|}{ Change in baPWV } \\
\hline & $\beta$ & S.E. & $P$ & $\beta$ & S.E. & $P$ \\
\hline Treatment & 4.956 & 0.682 & $<0.0001$ & -74.492 & 26.717 & 0.006 \\
\hline Change in triglyceride & -0.006 & 0.002 & 0.014 & 0.267 & 0.107 & 0.014 \\
\hline Age & 0.060 & 0.030 & 0.052 & 2.763 & 1.219 & 0.026 \\
\hline Change in HOMA & 0.548 & 0.293 & 0.065 & & & \\
\hline Change in diastolic blood pressure & & & & 3.824 & 1.219 & 0.002 \\
\hline Change in cholesterol & & & & 0.739 & 0.428 & 0.088 \\
\hline
\end{tabular}

*All variables left in the model are significant at the 0.1500 level. 
observed favorable effect of rosiglitazone on PWV in non-diabetics is promising.

During rosiglitazone treatment, no reduction in HOMA was observed, whereas HOMA increased in the control group. We do not know exactly why this somewhat unexpected finding was observed. One possible explanation is that TZDs may mainly act on postprandial insulin sensitivity in prediabetes or non-diabetic MetS in Koreans. Actually, post-OGTT insulin levels were also significantly decreased in the rosiglitazone group compared with the control group. Another possible explanation is the short-term treatment of relatively low doses of rosiglitazone. According to Raskin et al. (28), rosiglitazone monotherapy (2 $\mathrm{mg}$ twice daily) for 8 weeks did not reduce plasma insulin concentrations compared with placebo in T2DM (28). In the present study, rosiglitazone-treated subjects showed a small decrease in fasting blood glucose (3.9\% from baseline) without a reduction in $\mathrm{HbA1c}$ levels. Moreover, changes in PWV were not associated with changes in glucose level or HOMA by multiple regression analysis. In addition, lipid profiles were unchanged in the rosiglitazone group, whereas serum triglyceride levels were significantly reduced in the control group. These results, which contradict previous findings in the literature, are probably because of the encouragement of patients to adhere to a low cholesterol diet throughout the study.

The data presented here suggest that the observed reduction in PWV in the rosiglitazone group may have resulted from additional effects of rosiglitazone beyond metabolic control. A possible explanation for the observed PWV change might be that rosiglitazone directly effects PPAR- $\gamma$ activation in the vascular wall. Much evidence favors the direct vascular affects of PPAR- $\gamma$ agonists on atherosclerosis. PPAR- $\gamma$ is expressed in endothelial cells, VSMCs, macrophages, and T cells, and it may have various anti-atherogenic properties in the vascular wall. Several studies have suggested that TZDs enhance vasorelaxation in vascular smooth muscle $(29,30)$. Recently, Hetzel et al. (31) found that short-term treatment (21 days) of rosiglitazone in healthy subjects significantly improved vascular endothelial function without changes in blood glucose level, lipid profile, and HOMA. In our study, systolic and diastolic blood pressures were found to be significantly reduced in the rosiglitazone group; this is compatible with results obtained in non-diabetic hypertensive patients (32). Summarizing the results of these studiese (29-31) with those of the present study, it is postulated that the observed PWV change is mediated primarily by the direct action of rosiglitazone on the vascular wall.

Little information is available concerning the effects of TZDs on plasma adiponectin levels in non-diabetics, and even where data were not obtained in a randomized manner $(33,34)$. In the present study, rosiglitazone treatment markedly increased circulating adiponectin levels by $160 \%(P<0.001)$, whereas no change was observed in the control group $(P=0.21)$. This increment in adiponectin levels is similar in magnitude to that observed in T2DM (17). Yang et al. (17) observed an increase in plasma adiponectin along with weight gain after rosiglitazone treatment in T2DM. Unlike reports in T2DM including those of Yang et al. (17), rosiglitazone treatment showed no evidence of weight gain in the present study, and it was not different from results observed in non-diabetics $(8,9)$. In view of adiponectin's likely favorable effect on atherosclerosis, our findings suggest that rosiglitazone may have an anti-atherogenic effect in subjects with prediabetes or non-diabetic MetS. In addition to favorable changes in adiponectin levels, hsCRP levels were significantly reduced by rosiglitazone. The mean reduction in CRP of $43 \%$ due to rosiglitazone treatment in this study was of the same order of magnitude as the reduction achieved by high dose statin ( $40 \mathrm{mg}$ atorvastatin) in subjects with impaired fasting glucose (35).

Resistin is a newly discovered adipocytokine. Initial studies in rodents have suggested that circulating resistin levels are markedly elevated in obese mice, and that these are reduced by rosiglitazone (36). However, human resistin shares only $64 \%$ homology with murine resistin and is expressed at very low levels in adipocytes (37). Numerous epidemiological studies in humans have failed to provide a clear and consistent link between resistin expression in adipose tissue or circulating resistin levels and adiposity or insulin resistance (37). Contrary to these reports, Reilly et al. (38) suggested that resistin may represent a novel link between metabolic signals, inflammation, and atherosclerosis. Although it has been reported that TZDs reduce plasma resistin levels in T2DM patients (39), no report is available concerning their effects in nondiabetics. In the present study, plasma resistin levels were found to be unchanged by rosiglitazone. Thus, the role of resistin in atherosclerosis and the relation between TZD and resistin levels require further study.

Several limitations of our study must be acknowledged. First, the study was not performed in a doubleblind placebo-controlled fashion. Thus, it is possible that the rosiglitazone group had more intensive lifestyle changes than the control group, which could have exaggerated the favorable effect of rosiglitazone. However, post-hoc analysis revealed no significantly different life-style changes between the groups (data not shown). Secondly, our study was performed using a small number of subjects over a short period of time. Whether the observed favorable effects of rosiglitazone on various surrogate markers of atherosclerosis in non-diabetics translate into actual benefits in terms of cardiovascular morbidity and mortality must await further investigation.

In conclusion, this study has clearly demonstrated that rosiglitazone treatment for 12 weeks leads to favorable effects on plasma adiponectin, hsCRP, and baPWV in subjects with prediabetes or non-diabetic MetS. Thus 
the present findings suggest that rosiglitazone has a vasoprotective effect in these two subpopulations.

\section{Acknowledgements}

This study was undertaken as an investigator-initiated research protocol and was supported by grants from Korea University Medical College and the Medical Research Center for Environmental Toxicogenomic and Proteomics, and funded by Korea Science and Engineering Foundations and the Ministry of Science and Technology. The authors declare that there is no conflict of interest that would prejudice the impartiality of this scientific work.

\section{References}

1 Spiegelman BM. PPAR-gamma: adipogenic regulator and thiazolidinedione receptor. Diabetes $1998 \mathbf{4 7} 507-514$.

2 Marx N, Duez H, Fruchart JC \& Staels B. Peroxisome proliferatoractivated receptors and atherogenesis: regulators of gene expression in vascular cells. Circulation Research 200494 $1168-1178$.

3 Marx N \& Hombach V. Peroxisome proliferator-activated receptors (PPARs) in the vessel wall: new regulators of gene expression in vascular cells (in German). Zeitschrift für Kardiologie 200190 $470-477$.

4 Goetze S, Xi XP, Kawano H, Gotlibowski T, Fleck E, Hsueh WA \& Law RE. PPAR gamma-ligands inhibit migration mediated by multiple chemoattractants in vascular smooth muscle cells. Journal of Cardiovascular Pharmacology 199933 798-806.

5 Satoh N, Ogawa Y, Usui T, Tagami T, Kono S, Uesugi H, Sugiyama H, Sugawara A, Yamada K, Shimatsu A, Kuzuya H \& Nakao K. Antiatherogenic effect of pioglitazone in type 2 diabetic patients irrespective of the responsiveness to its antidiabetic effect. Diabetes Care 200326 2493-2499.

6 Koshiyama H, Shimono D, Kuwamura N, Minamikawa J \& Nakamura Y. Rapid communication: Inhibitory effect of pioglitazone on carotid arterial wall thickness in type 2 diabetes. Journal of Clinical Endocrinology and Metabolism 2001863452 -3456.

7 Dormandy JA, Charbonnel B, Eckland DJ, Erdmann E, MassiBenedetti M, Moules IK, Skene AM, Tan MH, Lefebvre PJ, Murray GD, Standl E, Wilcox RG, Wilhelmsen L, Betteridge J, Birkeland K, Golay A, Heine RJ, Koranyi L, Laakso M, Mokan M, Norkus A, Pirags V, Podar T, Scheen A, Scherbaum W, Schernthaner G, Schmitz O, Skrha J, Smith U \& Taton J. Secondary prevention of macrovascular events in patients with type 2 diabetes in the PROactive Study (PROspective pioglitAzone Clinical Trial In macroVascular Events): a randomised controlled trial. Lancet 2005366 1279-1289.

8 Wang TD, Chen WJ, Lin JW, Chen MF \& Lee YT. Effects of rosiglitazone on endothelial function, C-reactive protein, and components of the metabolic syndrome in nondiabetic patients with the metabolic syndrome. American Journal of Cardiology 200493362 -365.

9 Sidhu JS, Kaposzta Z, Markus HS \& Kaski JC. Effect of rosiglitazone on common carotid intimamedia thickness progression in coronary artery disease patients without diabetes mellitus. Arteriosclerosis Thrombosis and Vascular Biology 200424 930-934.

10 Blacher J, Asmar R, Djane S, London GM \& Safar ME. Aortic pulse wave velocity as a marker of cardiovascular risk in hypertensive patients. Hypertension 199933 1111-1117.

11 Amar J, Ruidavets JB, Chamontin B, Drouet L \& Ferrieres J. Arterial stiffness and cardiovascular risk factors in a population-based study. Journal of Hypertension 200119 381-387.
12 Cohn JN. Vascular wall function as a risk marker for cardiovascular disease. Journal of Hypertension 199917 (Suppl 5) S41-S44.

13 Laurent S, Boutouyrie P, Asmar R, Gautier I, Laloux B, Guize L, Ducimetiere P \& Benetos A. Aortic stiffness is an independent predictor of all-cause and cardiovascular mortality in hypertensive patients. Hypertension 200137 1236-1241.

14 Kershaw EE \& Flier JS. Adipose tissue as an endocrine organ. Journal of Clinical Endocrinology and Metabolism 2004892548 -2556.

15 Yamauchi T, Hara K, Kubota N, Terauchi Y, Tobe K, Froguel P, Nagai R \& Kadowaki T. Dual roles of adiponectin/Acrp30 in vivo as an anti-diabetic and anti-atherogenic adipokine. Current Drug Targets-Immune, Endocrine \& Metabolic Disorders $2003 \quad 3$ $243-254$.

16 Pischon T, Girman CJ, Hotamisligil GS, Rifai N, Hu FB \& Rimm EB. Plasma adiponectin levels and risk of myocardial infarction in men. Journal of the American Medical Association 2004291 $1730-1737$.

17 Yang WS, Jeng CY, Wu TJ, Tanaka S, Funahashi T, Matsuzawa Y, Wang JP, Chen CL, Tai TY \& Chuang LM. Synthetic peroxisome proliferator-activated receptor-gamma agonist, rosiglitazone, increases plasma levels of adiponectin in type 2 diabetic patients. Diabetes Care 200225 376-380.

18 American Diabetes Association. Standards of medical care in diabetes. Diabetes Care 200427 S15-S35.

19 Malik S, Wong ND, Franklin SS, Kamath TV, L'italien GJ, Pio JR \& Williams GR. Impact of the metabolic syndrome on mortality from coronary heart disease, cardiovascular disease, and all causes in United States adults. Circulation $20041101245-1250$.

20 Executive Summary of The Third Report of The National Cholesterol Education Program (NCEP) Expert Panel on Detection, Evaluation, And Treatment of High Blood Cholesterol In Adults (Adult Treatment Panel III). Journal of the American Medical Asociation $20012852486-2497$.

21 World Health Organisation. The Asia-Pacific perspective refining obesity and its treatment. ITOF, 2000.

22 Youn BS, Yu KY, Park HJ, Lee NS, Min SS, Youn MY, Cho YM, Park YJ, Kim SY, Lee HK \& Park KS. Plasma resistin concentrations measured by enzyme-linked immunosorbent assay using a newly developed monoclonal antibody are elevated in individuals with type 2 diabetes mellitus. Journal of Clinical Endocrinology and Metabolism 200489 150-156.

23 Yamashina A, Tomiyama H, Takeda K, Tsuda H, Arai T, Hirose K, Koji Y, Hori S \& Yamamoto Y. Validity, reproducibility, and clinical significance of noninvasive brachial-ankle pulse wave velocity measurement. Hypertension Research 200225 359-364.

24 Kubo T, Miyata M, Minagoe S, Setoyama S, Maruyama I \& Tei C. A simple oscillometric technique for determining new indices of arterial distensibility. Hypertension Research 200225 351-358.

25 Kobayashi K, Akishita M, Yu W, Hashimoto M, Ohni M \& Toba K. Interrelationship between non-invasive measurements of atherosclerosis: flow-mediated dilation of brachial artery, carotid intima-media thickness and pulse wave velocity. Atherosclerosis 2004173 13-18.

26 Koji Y, Tomiyama H, Ichihashi H, Nagae T, Tanaka N, Takazawa K, Ishimaru S \& Yamashina A. Comparison of anklebrachial pressure index and pulse wave velocity as markers of the presence of coronary artery disease in subjects with a high risk of atherosclerotic cardiovascular disease. American Journal of Cardiology $200494868-872$.

27 Stakos DA, Schuster DP, Sparks EA, Wooley CF, Osei K \& Boudoulas H. Long term cardiovascular effects of oral antidiabetic agents in non-diabetic patients with insulin resistance: double blind, prospective, randomised study. Heart 200591 589-594.

28 Raskin P, Rappaport EB, Cole ST, Yan Y, Patwardhan R \& Freed MI. Rosiglitazone short-term monotherapy lowers fasting and postprandial glucose in patients with type II diabetes. Diabetologia $200043278-284$.

29 Buchanan TA, Meehan WP, Jeng YY, Yang D, Chan TM, Nadler JL, Scott S, Rude RK \& Hsueh WA. Blood pressure lowering by piogli- 
tazone. Evidence for a direct vascular effect. Journal of Clinical Investigation $199596354-360$.

30 Plutzky J. Peroxisome proliferator-activated receptors in vascular biology and atherosclerosis: emerging insights for evolving paradigms. Current Atherosclerosis Report 20002 327-335.

31 Hetzel J, Balletshofer B, Rittig K, Walcher D, Kratzer W Hombach V, Haring HU, Koenig W \& Marx N. Rapid effects of rosiglitazone treatment on endothelial function and inflammatory biomarkers. Arteriosclerosis Thrombosis and Vascular Biology 200525 1804-1809.

32 Raji A, Seely EW, Bekins SA, Williams GH \& Simonson DC. Rosiglitazone improves insulin sensitivity and lowers blood pressure in hypertensive patients. Diabetes Care 200326 172-178.

33 Osei K, Gaillard T, Kaplow J, Bullock M \& Schuster D. Effects of rosglitazone on plasma adiponectin, insulin sensitivity, and insulin secretion in high-risk African Americans with impaired glucose tolerance test and type 2 diabetes. Metabolism 200453 $1552-1557$.

34 Hammarstedt A, Sopasakis VR, Gogg S, Jansson PA \& Smith U. Improved insulin sensitivity and adipose tissue dysregulation after short-term treatment with pioglitazone in non-diabetic, insulin-resistant subjects. Diabetologia 2005 48 96-104.
35 Costa A, Casamitjana R, Casals E, Alvarez L, Morales J, Masramon X, Hernandez G, Gomis R \& Conget I. Effects of atorvastatin on glucose homeostasis, postprandial triglyceride response and C-reactive protein in subjects with impaired fasting glucose. Diabetic Medicine $200320743-745$.

36 Steppan CM, Bailey ST, Bhat S, Brown EJ, Banerjee RR, Wright CM, Patel HR, Ahima RS \& Lazar MA. The hormone resistin links obesity to diabetes. Nature $2001 \mathbf{4 0 9} 307-312$.

37 Banerjee RR \& Lazar MA. Resistin: molecular history and prognosis. Journal of Molecular Medicine 200381 218-226.

38 Reilly MP, Lehrke M, Wolfe ML, Rohatgi A, Lazar MA \& Rader DJ. Resistin is an inflammatory marker of atherosclerosis in humans. Circulation $2005111932-939$.

39 Bajaj M, Suraamornkul S, Hardies LJ, Pratipanawatr T \& Defronzo RA. Plasma resistin concentration, hepatic fat content, and hepatic and peripheral insulin resistance in pioglitazone-treated type II diabetic patients. International Journal of Obesity Related Metabolic Disorders 200428 783-789.

Received 1 October 2005

Accepted 23 November 2005 